\title{
NANOINDENTATION AS A METHOD FOR DETERMINING THE MECHANICAL PROPERTIES OF COLD SPRAY COATINGS
}

\author{
Medard Makrenek \\ Faculty of Management and Computer Modelling, Kielce, Poland \\ *E-mail of corresponding author: fizmm@tu.kielce.pl
}

\section{Resume}

The paper presents the methodology behind the statistical selection of input parameters using the example of spraying two cold-sprayed coatings. The $\mathrm{Ti}$

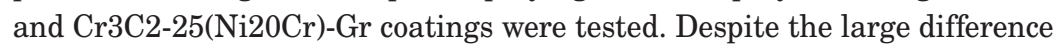
in the structure of these coatings, nanoindentation studies were carried out focusing on the nano hardness $\mathrm{H}$ and elastic modulus $\mathrm{E}$. Based on the four input parameters and two output parameters, a 2-level factorial 2(k-p) experimental design was performed. The conducted analysis showed the significant influence of the spray distance on the $\mathrm{H}$ and $\mathrm{E}$ values in the case of the Ti coating. The input parameters of the spray distance and the type of carrier gas used turned out to be statistically significant in the case of the cermet coating. Taking into account the statistical analysis, the coatings were sprayed with modified values of the input parameters.

\section{Article info}

Received 22 October 2020

Accepted 11 January 2021

Online 23 June 2021

\section{Keywords:}

nanoindentation, hardness, elastic modulus, cold spray, 2-level factorial statistics

\section{Introduction}

The basic functions of thermal spray coatings include different applications, e.g. wear-resistant and regenerating coatings [1-4]. Coatings with a thickness of a few to several $\mathrm{mm}$ make it possible to produce individual products, thus being classified as additive technologies [5]. Cold spraying is the latest generation of this technology and is now widely used in production engineering, as well as in implantology [6]. The basic properties connecting these coatings are the requirements related to the hardness $\mathrm{H}$ and elastic modulus E. In the article, $2^{(\mathrm{k}-\mathrm{p})}$ optimization methods were tested for the selection of controlled parameters of the experiment to obtain high values of $\mathrm{H}$ and $\mathrm{E}$ of coatings applied with the SC technology. The problem of $2^{(\mathrm{k}-\mathrm{p})}$ optimization is not often found in the literature on the CS superimposition technique. Two coatings with different microstructure were selected for the study. Nanoindentation tests were performed on these two coatings. The coatings were deposited by a cold spray process. For the tested compounds, this method ensures the absence of phase transitions during the coating application process. The material does not melt, thus minimising the influence of the process on properties of the resulting coating.

The titanium coating, applied by the cold spraying, takes over the properties of titanium. The coating is durable and resistant to various chemical and physical factors. Titanium has a low density but is stiff and resistant to corrosion. It is biologically compatible with human tissues and is neutral and harmless to them, which gives it further application possibilities. The other tested coating is made of the $\mathrm{Cr}_{3} \mathrm{C}_{2}-25$ (Ni20Cr)- $\mathrm{Gr}$ composite powder [7]. This cermet is a good material for use in the production of machine parts or the aviation industry, improving wear parameters and reducing the impact of corrosion. The cold spray technology avoids the gradation of $\mathrm{Cr}_{3} \mathrm{C}_{2}$ carbides into soft $\mathrm{Cr}_{23} \mathrm{C}_{6}$ compounds and eliminates the influence of oxygen in the coating process [8]. The research focused on the hardness $\mathrm{H}$ and elastic modulus E. The parameter values, controlled by the researcher, should be indicated and their values determined so that the coating obtains its planned properties: hardness H, elastic modulus E. Values of the parameters controlled by the researcher should be indicated and their values determined so that the coating will reach its planned properties.

Nanoindentation research is an excellent tool for testing mechanical properties. This is due to the essence of the measurement technique's highly localized testing points. These tests are generally not destructive and, at the same time, enable the measurement of a diverse set of properties, including hardness and elastic modulus [9-11]. Modern testing devices enable quick measurement, which makes it possible to build maps containing from several to several dozen or even several hundred measurement points within several dozen minutes. Interpreting the results of nanoindentation requires taking various factors into account, such 
as indentation spacing, strain rate effects and the indentation depth. Due to the load function of the indenter, a tester was used to measure the hardness and elastic modulus. A comprehensive approach to the problems of nanoindentation measurements is described in the work of Chromik et al. [12]. Nanoindentation research complements classical research [13].

Before qualifying the coating for technical applications, a tedious process of selecting technological (controlled) parameters was carried out. Controlled parameters are determined by the applied technique of cold spraying. In the discussed cold spraying, the controlled parameters include the temperature $\mathrm{T}$, pressure $p$, distance $d$ and speed of the gun V. The choice of these values determines the properties of the coating. In the present investigation, four input factors were considered as variables at two levels (low and high) to establish a 2-level factorial $2^{(\mathrm{k}-\mathrm{p})}$ experimental design.

The aim of this work was to analyse the influence of input values on the output values and to modify them to obtain the best values of $\mathrm{H}$ and $\mathrm{E}$.

\section{Experimental and research}

\subsection{Design of experiment}

Many conditions lead to different types of experimental design. It is advisable to create an experiment plan in which the main effects are not correlated with each other and, in some cases, are not correlated with interactions of the input quantities. In many cases, it can be assumed that the factors influencing the final result take only two values. Does a change in the factor value affect the final result and what is its share in the final result? The solution to this problem would be to change the input quantities values according to a complete plan, that is, to try all possible combinations of the values of the input quantities that make up the design of the experiment plan. Unfortunately, the number of necessary measurements (layouts) grows exponentially $2^{\mathrm{n}}$, where $\mathrm{n}$ is the number of input quantities. In order to test the influence of 4 input quantities, the necessary number of measurements is $2^{4}=16$. This is already a significant number of measurements. Use of the fractional designs makes it possible to reduce the number of measurements. When planning an experiment based on a $2^{(\mathrm{k}-\mathrm{p})}$ fractional design, the number of input quantities to be tested, the number of plan designs and whether there is a division into blocks, should be taken into account. In addition to these basic considerations, it should also be considered whether the number of layouts would provide the required plan resolution and degree of entanglement for critical-order interactions at a given resolution.

Experiment planning allows two basic questions to be answered:

1. How should an optimal experience be planned?
2. How should the obtained research results be analysed?

In cold gas spraying processes, it is assumed that the coating property (output parameter) is related to the input factors of the spraying process by a mathematical relationship:

$y=f\left(x_{n}\right)$,

where $x_{n}$ refers to the input factors. It is important to plan the experiment with a minimum number of input factors so that the process of selecting the best output value is not complicated. It seems that the following linear function meets our expectations [14].

$y=a_{0}+a_{1} x_{1}+\cdots+a_{n} x_{n}$,

where $a_{n}$ is the linear regression coefficient and $\mathrm{n}$ is the number of input parameters.

In the first-order two-level programs, the input factors are normalized to two levels: upper (1) and lower (-1) and the central values are calculated as the arithmetic mean of the input factor. The significance of the coefficients was assessed with the use of ANOVA, $\mathrm{F}$ and $\mathrm{P}$ tests. The quality of the obtained results is presented in Pareto diagrams or profiles of approximated values and utility. The resulting coatings were tested for their mechanical properties by examining the nano hardness $\mathrm{H}$ and elastic modulus E. The research used a nano tester with a Berkovich diamond indenter (E $1140 \mathrm{GPa}, \mathrm{v}_{\mathrm{i}}$ - 0.07). The following input factors were selected for the Ti coating: temperature $\mathrm{T}\left[{ }^{\circ} \mathrm{C}\right]$, pressure $\mathrm{p}$ [bar], distance of the spray head from the substrate $d$ $[\mathrm{mm}]$ and the speed of the gun $\mathrm{V}[\mathrm{mm} / \mathrm{s}]$. In the case of the composite coating, the following parameters were selected: graphite share $u[\%]$, gas $\left[\mathrm{N}_{2}, \mathrm{He}\right]$, distance $\mathrm{d}[\mathrm{mm}]$ and the head speed $\mathrm{V}[\mathrm{mm} / \mathrm{s}]$. The new values of the input factors were estimated in proportion to coefficients of the linear Equation (2), determined for the nano hardness $\mathrm{H}$ and elastic modulus E. For example, the temperature value for the titanium coating is calculated as:

$$
\begin{aligned}
& T_{N}=T_{-1}+\left(T_{1}-T_{-1}\right) * a_{k N}, \\
& a_{k N}=\frac{a_{k H}+a_{k E}}{\sum_{i}\left(a_{i H}+a_{i E}\right)},
\end{aligned}
$$

where: $\mathrm{T}_{\mathrm{N}}$ - new value of the input factor ( $\mathrm{T}$ - temperature), $a_{k H}$ and $a_{k E}$ determined constants in linear equations for the nano hardness $\mathrm{H}$ and elastic modulus $\mathrm{E}$.

\subsection{Materials and processing}

In this study, two coatings were made of $\mathrm{Ti}$ and $\mathrm{Cr}_{3} \mathrm{C}_{2}$-25(Ni20Cr)-Gr powders, which were applied by the cold spraying technology, using the Impact Innovations $5 / 8$ system. The grain-size distribution of the powders 


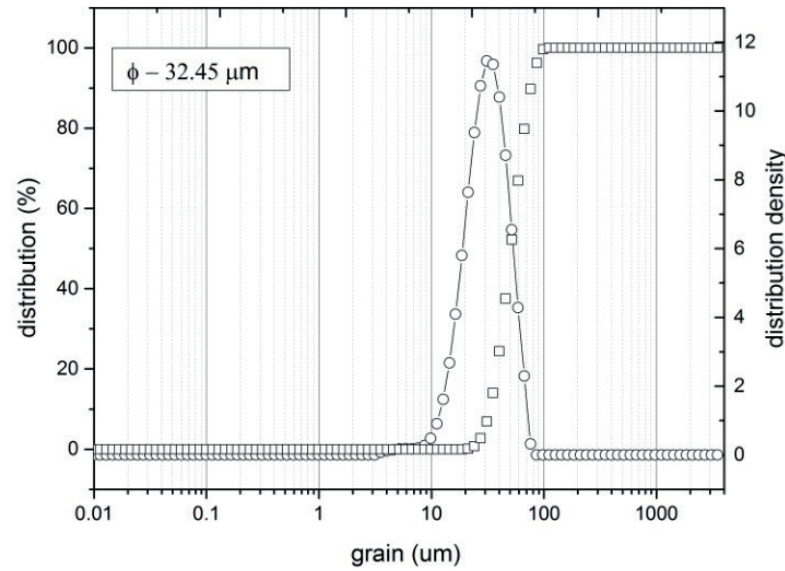

Figure 1 Grain size distributions of Ti. Titanium grain $d_{10}=32.06 \mu \mathrm{m}, d_{50}=51.41 \mu \mathrm{m}, d_{90}=75.07 \mu \mathrm{m}$

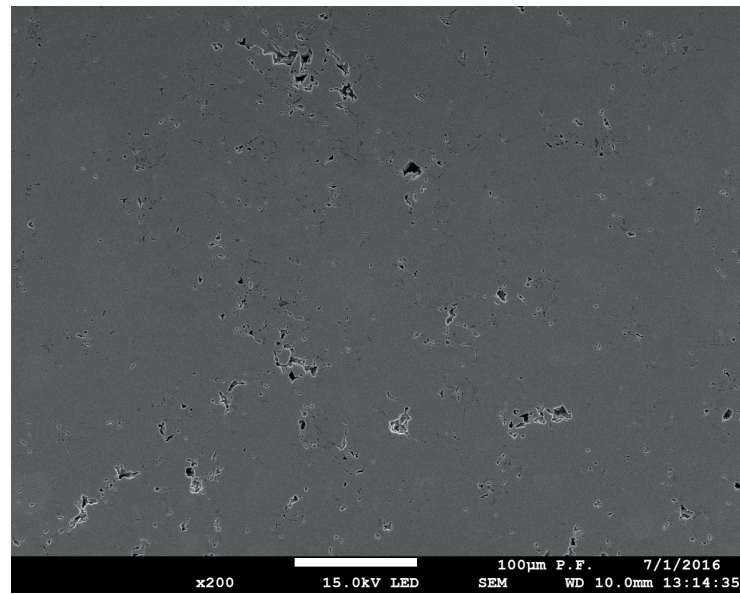

Figure 2 Microstructure of the titanium coating

was measured by a Malvern Mastersizer 3000 laser analyser. Substrate samples were made from a 7075 Al alloy with dimensions of $400 \times 30 \times 5 \mathrm{~mm}$. Prior to the cold spraying, the substrate was grit-blasted. The cold-sprayed samples were deposited according to the parameters presented in Table 1 and Table 2 . A scanning electron microscope (SEM - E-SEM FEI $\mathrm{XL} 30$ ) was used to characterise the morphology of the obtained coatings. For the cross-section observations, coatings were embedded in a resin and polished using a diamond suspension. Hardness tests were performed on polished cross-sections of the sprayed coatings using a Nanovea tester with a Berkovich indenter, applying a load of $20 \mathrm{mN}$ and a loading rate of $80 \mathrm{mN} / \mathrm{min}$.

\section{Titanium}

The first coating is titanium powder, the second is $\mathrm{Cr}_{3} \mathrm{C}_{2}-25(\mathrm{Ni20Cr})$ cermet. Figure 1 shows the particle size distribution of the powders based on which the tested coatings were formed. The dominant size of the titanium grains are grains of a diameter of $32.45 \mu \mathrm{m}$.

The distribution curve shows the asymmetry of the grain size distribution because $d_{50}=51.41 \mu \mathrm{m}$. In Figure 2 is shown a Ti coating applied using the cold spray

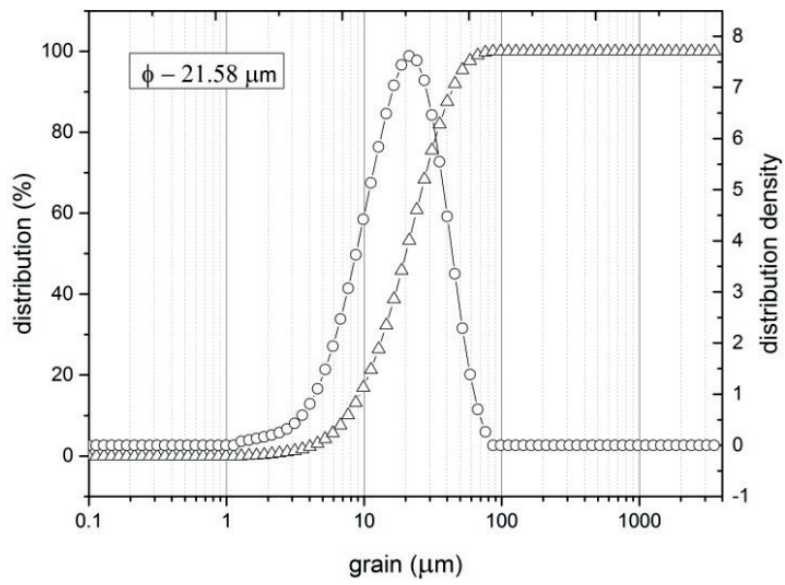

Figure 3 Grain size distributions of $\mathrm{Cr}_{3} \mathrm{C}_{2}-25(\mathrm{Ni20 \textrm {Cr }})-\mathrm{Gr}$. Cermet grains $d_{10}=4.04 \mu \mathrm{m}, d_{50}=19.7 \mu \mathrm{m}, d_{90}=41.33 \mu \mathrm{m}$

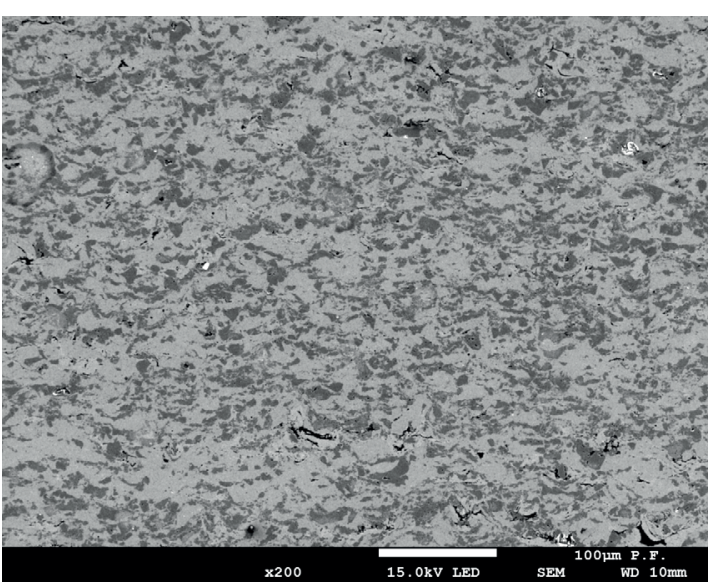

Figure 4 Microstructure of the $\mathrm{Cr}_{3} \mathrm{C}_{2}-25(\mathrm{Ni2OCr})-\mathrm{Gr}$ coating

technology. It is a single-component coating.

$\mathrm{Cr}_{3} \mathrm{C}_{2}-25(\mathrm{Ni20Cr})-\mathrm{Gr}$

The distribution of the size of the studied grains and their distribution density asymmetry can be seen. The distribution density curve reaches its maximum for $21.58 \mu \mathrm{m}$ and the $\mathrm{d}_{50}$ of the normal read is $19.7 \mu \mathrm{m}$.

Figure 4 shows a micrograph of the $\mathrm{Cr}_{3} \mathrm{C}_{2}$ 25(Ni2OCr)-Gr coating micro structure. The photomicrograph clearly shows the brighter areas corresponding to $\mathrm{Ni} 20 \mathrm{Cr}$, while the darker areas reflect the places containing $\mathrm{Cr}_{3} \mathrm{C}_{2}$. These grains differ in hardness. The heterogeneity of the coating is significantly reflected in the values of the tested quantities $\mathrm{H}$ and $\mathrm{E}$.

\section{Experiments' design, results and discussion}

In the tested titanium coating, the controlled parameters include the process temperature, gas pressure, distance from which the coating will be applied and the speed of the robot arm. The values of the control parameters influence the properties of the sprayed material. For the titanium coating, four values 


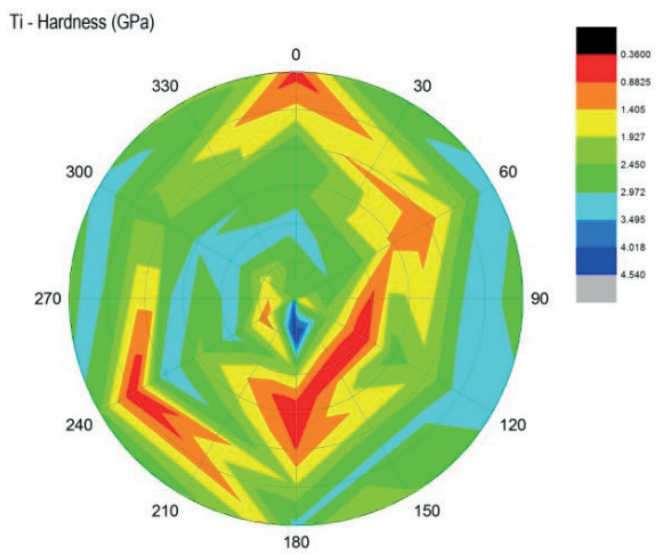

Figure 5 Hardness map for the Ti coating obtained for the data from the second variant of the plan (Table 1)

Table 1 The DOE matrix for the Ti coatings deposition

\begin{tabular}{ccccccc}
\hline trial & \multicolumn{3}{c}{ input parameters } & \multicolumn{2}{c}{ output parameters } \\
\cline { 2 - 6 } no. & $\mathrm{T}$ & $\mathrm{p}$ & $\mathrm{d}$ & $\mathrm{V}$ & $\mathrm{H}(\mathrm{GPa})$ & $\mathrm{E}(\mathrm{GPa})$ \\
\hline 1 & 700 & 30 & 30 & 300 & $2.5 \pm 0.2$ & $102 \pm 9$ \\
2 & 800 & 30 & 30 & 500 & $2.6 \pm 0.2$ & $95 \pm 7$ \\
3 & 700 & 30 & 500 & $2.3 \pm 0.3$ & $102 \pm 12$ \\
4 & 800 & 45 & 50 & 300 & $2.9 \pm 0.1$ & $151 \pm 6$ \\
5 & 700 & 30 & 50 & 500 & $3.0 \pm 0.1$ & $163 \pm 7$ \\
6 & 800 & 30 & 50 & 300 & $2.9 \pm 0.2$ & $163 \pm 8$ \\
7 & 700 & 45 & 30 & 500 & $3.0 \pm 0.1$ & $176 \pm 7$ \\
8 & 800 & 45 & & & $3.1 \pm 0.1$ & $151 \pm 10$ \\
\hline
\end{tabular}

were adopted from the following ranges: temperature $\mathrm{T}\left[{ }^{\circ} \mathrm{C}\right] 700-800$, pressure $\mathrm{p}$ [bar] 30-45, distance $1[\mathrm{~mm}]$ 30-50 and head speed V [mm/s] 300-500.

The coatings were prepared as planned in Table 1 and then the hardness and elastic modulus were measured for each of them. Measurements were carried out on the cross-sections by performing the $\mathrm{H}$ and $\mathrm{E}$ tests. Further studies included mean values of the output parameters, which were analysed $2^{(\mathrm{k}-\mathrm{p})}$. The $\mathrm{H}$ and $\mathrm{E}$ values from the measuring points formed hardness maps and elastic modulus maps, respectively. An example of a hardness map for the Ti coating obtained for the second configuration of input parameters from Table 1 is shown in Figure 5. In this figure, the dominant colour is about $2.6 \mathrm{GPa}$. Average and error values were calculated using the normal hardness distribution.

Table 1 shows the design of the experiment with the input parameter values for nano hardness $\mathrm{H}$ and $\mathrm{E}$.

The collected results from Table 1 were analysed statistically using ANOVA and $2^{(\mathrm{k}-\mathrm{p})}$. The coefficients of linear Equation (2) were calculated.

$y=a_{0}+\sum_{n=1}^{4} a_{i} x_{i}=a_{0}+T x_{1}+p x_{2}+d x_{3}+V x_{4}$

where: $\mathrm{y}$ is output value, $a_{0}$ average value, $a_{i}$ coefficients and $x_{i}$ values of the input quantities.

For the Ti coating, the estimated nano hardness $\mathrm{H}$ value is given by the relationship:
$H_{\text {nano }}=2.787+T * 0.0875+p * 0.0375+$

$+d * 0.125-V * 0.0375$.

Graphical presentation of the contribution of individual factors to the hardness of the coating is presented in Pareto diagram. In the cold gas spraying experiment, the distance has the greatest influence on hardness, while the temperature is slightly less influential.

The presented diagram shows the influence of the input quantities on the nano hardness of the coating. Statistical analyses showed that values of the input quantities had no significant influence on the nano painting value of the Ti coating. As can be seen from the Pareto diagram (Figure 6), the distance has the greatest influence on nano hardness, but it is not a statistically significant one $(\mathrm{F}=8.75, \mathrm{p}=0.59)$. A similar analysis was performed by examining the elastic modulus and Figure 7 presents profiles of approximated values and utility. Similarly to the applied hardness, the distance has the greatest influence. In this case, the distance has a statistically significant effect $(\mathrm{F}=14.58$, $\mathrm{p}=0.031$ ).

The diagrams of Figure 7 emphasise the meaning of the input quantities values. The diagram of the utility of the distance differs the most from the level, thus it provides information about the significant influence of $d$ on the value of the elastic modulus. The results of the above analysis reflect the coefficients in: 


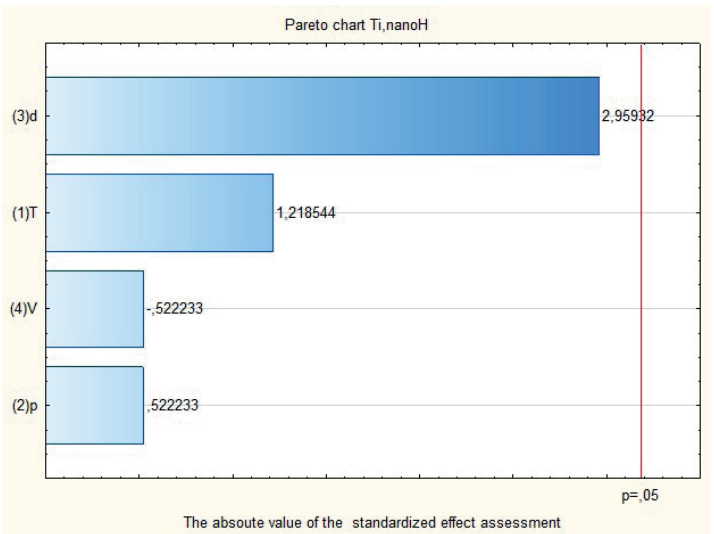

Figure 6 The Pareto diagram for the Ti coating, nano hardness $H$

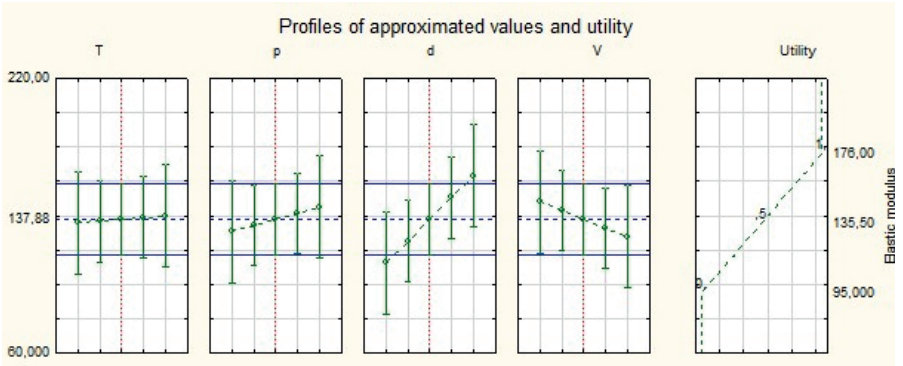

Figure 7 Profiles of approximate values for the Ti coating including elastic modulus

Table 2 The DOE matrix for deposition of the $\mathrm{Cr}_{3} \mathrm{C}_{2}-25$ (Ni20Cr)-Gr coatings

\begin{tabular}{ccccccc}
\hline \multirow{2}{*}{$\begin{array}{c}\text { trial } \\
\text { no. }\end{array}$} & \multicolumn{2}{c}{ input parameters } & \multicolumn{2}{c}{ output parameters } \\
\hline 1 & $\mathrm{U}$ & gas & $\mathrm{d}$ & $\mathrm{V}$ & $\mathrm{H}(\mathrm{GPa})$ & $\mathrm{E}(\mathrm{GPa})$ \\
2 & 5 & $\mathrm{~N}$ & 20 & 200 & $5.1 \pm 0.4$ & $190 \pm 15$ \\
3 & 15 & $\mathrm{~N}$ & 20 & 400 & $5.4 \pm 0.3$ & $188 \pm 25$ \\
4 & 5 & $\mathrm{He}$ & 20 & 400 & $5.2 \pm 0.5$ & $181 \pm 19$ \\
5 & 15 & $\mathrm{He}$ & 20 & 200 & $5.1 \pm 0.3$ & $130 \pm 28$ \\
6 & 5 & $\mathrm{~N}$ & 40 & 400 & $4.6 \pm 0.6$ & $142 \pm 15$ \\
7 & 15 & $\mathrm{~N}$ & 40 & 200 & $5.0 \pm 0.4$ & $116 \pm 12$ \\
8 & 5 & $\mathrm{He}$ & 40 & 200 & $4.1 \pm 0.5$ & $123 \pm 19$ \\
\hline
\end{tabular}

$$
\begin{aligned}
& E=137.875+T * 2.125+p * 7.125+ \\
& +d * 20.375-V * 10.125 .
\end{aligned}
$$

Another input factor, influencing the output factor (E), is the speed of the spray head V. However, this effect is not statistically significant $(\mathrm{F}=2.32, \mathrm{p}=0.22)$.

Optimisation tests for of the values cermet were carried out in a similar way, except that the input parameters were graphite by weight, gas, distance and speed of the robot arm.

The granulometry of the cermet grains is shown in Figure 3. The grains can be assigned a size of $\phi$ $21.58 \mu \mathrm{m}$. A cermet micrograph is shown in Figure 4. Optimisation tests of the cermet coating were carried out according to the plan presented in Table 2. The last two columns of the table contain of the values mean values of nano hardness and elastic modulus calculated for 72 measurement impressions.

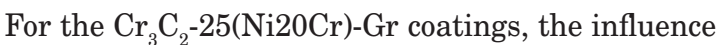
of individual input factors on the nano hardness $\mathrm{H}$ output factor is different. The type of gas used in the spraying process $(\mathrm{F}=12.22, \mathrm{p}=0.030)$ and the distance $(\mathrm{F}=28.17, \mathrm{p}=0.013)$ have a statistically significant influence on the nano hardness of the coating.

The equation estimating the value of nano hardness $\mathrm{H}$ takes the form:

$H_{\text {nano }}=6.912-u * 0.062-$ gas $* 0.337-$

$-d * 0.512-V * 0.137$.

A Pareto diagram (Figure 8) graphically shows influence of individual input factors on the nano hardness $\mathrm{H}$ of the $\mathrm{Cr}_{3} \mathrm{C}_{2}-25(\mathrm{Ni20Cr})-\mathrm{Gr}$ coating.

Figure 9 shows a polar map with distribution of the elastic modulus values for the cermet coating. The map was created based on 72 measurement points obtained in the first sample of the plan (Table 2). 


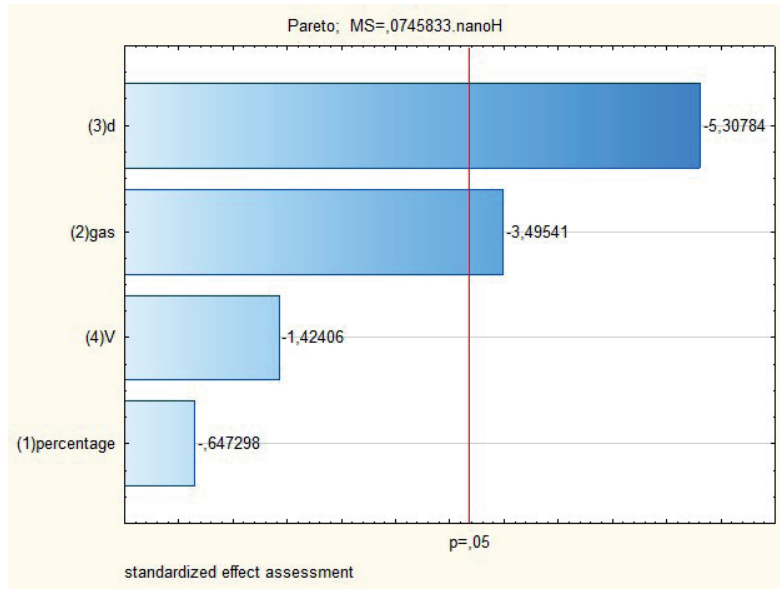

Figure 8 Graphical presentation of influence of individual input factors on the nano hardness $H$ of the cermet coating
$\mathrm{Cr}_{3} \mathrm{C}_{2}-25(\mathrm{Ni20Cr})-$ Elastic Modus (GPa)

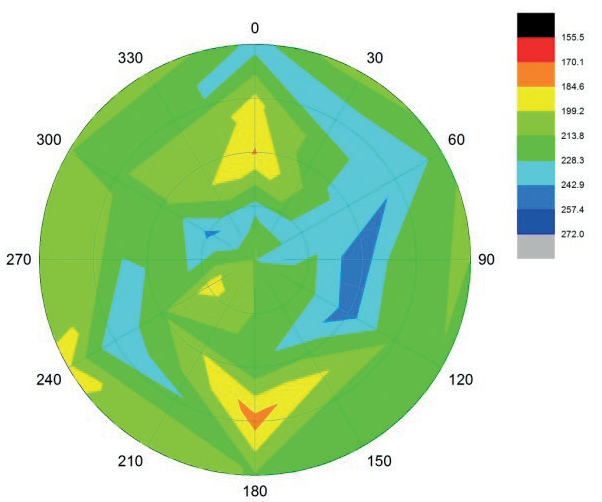

Figure 9 Map of the elastic modulus $E$ for the first coating of the $\mathrm{Cr}_{3} \mathrm{C}_{2}-25(\mathrm{Ni20 \textrm {Cr } )}$ - $\mathrm{Gr}$ composite compound

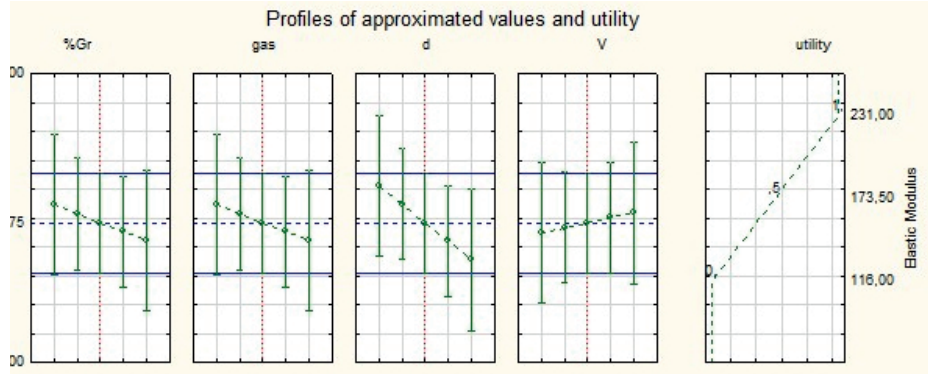

Figure 10 Profiles of approximate values for the cermet coating including elastic modulus

Table 3 New input factors and corresponding output factors

\begin{tabular}{|c|c|c|c|c|c|c|}
\hline \multirow{2}{*}{$\begin{array}{c}\text { sample } \\
\mathrm{Ti}\end{array}$} & \multicolumn{4}{|c|}{ new input factors } & \multicolumn{2}{|c|}{ output } \\
\hline & $\mathrm{T}$ & $\mathrm{p}$ & $\mathrm{d}$ & $\mathrm{V}$ & $\mathrm{H}$ & $\mathrm{E}$ \\
\hline \multirow{3}{*}{$\begin{array}{l}\mathrm{Cr}_{3} \mathrm{C}_{2}-25 \\
\text { (Ni20Cr)-Gr }\end{array}$} & 703 & 33 & 40 & 350 & $3.5 \pm 0.10$ & $195 \pm 11$ \\
\hline & $\mathrm{u}$ & gas & $d$ & $\mathrm{~V}$ & $\mathrm{H}$ & $\mathrm{E}$ \\
\hline & 7 & $78 \% \mathrm{~N}$ & 29 & 224 & $5.4 \pm 0.2$ & $235 \pm 11$ \\
\hline
\end{tabular}

The profiles of approximated values and utility of the elastic modulus $\mathrm{E}$ are shown in Figure 10. As in the case of nano hardness, the value of the elastic modulus is influenced the most by the distance $d$. In this case, the impact is significant $(\mathrm{F}=5.6, \mathrm{p}=0.094)$.

Profiles of approximate values and utility emphasize the importance of the input values. The utility diagram $\mathrm{d}$ deviates the most from the level, thus it provides information about the significant influence of distance on the elastic modulus' value. The result of the above analysis is reflected in the coefficients in the equation, where the distance factor is equal to 25.75 .

$$
\begin{aligned}
& E=943.5-u * 12.5-\text { gas } * 12.5- \\
& -d * 25.75+V * 6.75 .
\end{aligned}
$$

An important element of the DOE is preparation of the optimal input parameters and verification of output parameters. Based on linear Equations (6) and (7), new values of the input factors for the titanium coating ( $T, p$, $d, V$ ) were estimated. Equations (3) and (4) were used in the calculations. For example, the modified temperature in the Ti coating process is:

$$
\begin{aligned}
& T_{N}=T_{-1}+\left(T_{1}-T_{-1}\right) * a_{i N}= \\
& 700+\frac{(800-700) * 0.0875+2.125}{40.0235} \cong 703 .
\end{aligned}
$$

Calculations of the input factors for the cermet coating were performed in the same way. The calculation results are presented in Table 3.

The coatings formed from the new input factors have been tested for $\mathrm{H}$ and $\mathrm{E}$. The results of these tests are contained in Table 3. The values of $\mathrm{H}$ and $\mathrm{E}$ for the resulting coatings are slightly greater than the values before the optimisation of input parameter values.

\section{Conclusions}

A factorial experimental design (DOE) was established for the principal cold spray process parameters, such as temperature, pressure, distance and speed when applying a titanium coating. In the 
case of a cermet coating, the type of gas used, distance, velocities and percentage of graphite, were used. In the present investigation, the four input factors were considered as variables at two levels (low and high) to establish a 2-level factorial $2^{(\mathrm{k}-\mathrm{p})}$ experimental design.

1. Based on the nanoindentation tests of the Ti coating and the correction of the input parameters, an increase in the value of $\mathrm{H}$ by $13 \%$ and an increase in the value of $\mathrm{E}$ by $11 \%$ in relation to the highest values of Table 1 were obtained.

2. Based on the nanoindentation tests of the $\mathrm{Cr}_{3} \mathrm{C}_{2}$ 25(Ni20Cr)-Gr coating and corrections of the input parameters, an increase in the hardness value by
$9 \%$ and an increase in the $\mathrm{E}$ value by $23 \%$ compared to the highest values in Table 2 were obtained.

It follows from the above that the cold gas spraying process is a complex process. For the Ti coating, the key input parameter is the distance of the spray head from the substrate (d) and for the cermet coating it is also d, as well as the used gas.

\section{Acknowledgements}

This work is supported by the National Science Centre, Poland (Project No. 2017/25/B/ST8/02228).

\section{References}

[1] PAWLOWSKI, L. The science and engineering of thermal spray coatings. 2. ed. Chichester: J. Willey \& Sons Ltd, 2008. ISBN 0471490490.

[2] SCENDO, M., ZORAWSKI, W., STASZEWSKA, K., MAKRENEK, M., GORAL, A. Influence of surface pretreatment on the corrosion resistance of cold sprayed nickel coatings in acid chloride solution. Journal of Materials Engineering and Performance [online]. 2018, 27(4), p. 1725-1737. ISSN 1059-9495. Available from: https://doi.org/10.1007/s11665-018-3298-6

[3] ZORAWSKI, W., MAKRENEK, M., GORAL, A. Mechanical properties and corrosion resistance of HVOF sprayed coatings using nanostructured carbide powders. Archives of Metallurgy and Materials [online]. 2016, 61(4), p. 1839-1846. ISSN 1733-3490. Available from: https://doi.org/10.1515/amm-2016-0297

[4] OTMIANOWSKI, T., ANTOSZEWSKI, B., ZORAWSKI, W. Local laser treatment of tribological plasma sprayed coatings. In: 15th International Thermal Spray Conference: proceedings. 1998. p. 1333-1336.

[5] SILVA, F. S., CINCA, N., DOSTA, S., CANO, I. G., GUILEMANY, J. M., BENEDETTI, A. V. Cold gas spray coatings: basic principles, corrosion protection and applications. Ecletica Química Journal [online]. 2017, 42, p. 9-32. ISSN 1678-4618. Available from: https://doi.org/10.26850/1678-4618eqj.v42.1.2017.p09-32

[6] MAKRENEK, M., BELKA, R., ZORAWSKI, W., KOWALSKI, SZ., SZTORC, M., GORAL, A. Physical and mechanical properties of hydroxyapatite plasma sprayed materials applied in implantology. Medycyna Pracy [online], 2018, 69(6), p. 651-661. ISSN 0465-5893, eISSN 2353-1339. Available from: https://doi.org/10.13075/ mp.5893.00725

[7] WOLFE, D. E., EDEN, T. J., POTTER, J. K., JAROH, A. P. Investigation and characterization of Cr3C2-based wear-resistant coatings applied by the cold spray process. Journal of Thermal Spray Technology [online]. 2006, 15(3), p. 400-412. ISSN 1059-9630. Available from: https://doi.org/10.1361/105996306X124400

[8] MRDAK, M. Mechanical properties and microstructure of vacuum plasma sprayed Cr3C2-25(Ni20Cr) coatings. Vojnotehnicki Glasnik / Military Technical Courier. 2015, 63(2), p. 47-63. ISSN 0042-8469, eISSN 2217-4753.

[9] PHARR, G. M., HARDING, D. S., OLIVER, W. C. Measurement of fracture toughness in thin films and small volumes using nanoindentation methods. In: Mechanical properties and deformation behavior of materials having ultra-fine microstructures. Nastasti, M. Parkin, D. M., Gleiter, H. (eds.). Dordrecht, the Netherlands: Kluwer Academic Publishers, 1993. ISBN 978-94-011-1765-4, p. 449-461.

[10] GORAL, A., ZORAWSKI, W., MAKRENEK, M. The effect of the standoff distance on the microstructure and mechanical properties of cold sprayed. Surface and Coatings Technology [online]. 2019, 361, p. 9-18. ISSN 0257-8972. Available from: https://doi.org/10.1016/j.surfcoat.2019.01.006

[11] STEPIEN, A., SITARZ, M., LESNIAK, M. A Sustainable autoclaved material made of glass sand. Buildings [online]. 2019, 9(11), 232. eISSN 2075-5309. Available from: https://doi.org/10.3390/buildings9110232

[12]CHROMIK, R. R., ZHANG, Y. Nanomechanical testing of third bodies. Current Opinion in Solid State and Materials Science [online]. 2018, 22(4), p. 142-155. ISSN 1359-0286. Available from: https://doi.org/10.1016/j. cossms.2018.05.001

[13] HINTSALA, E. D., HANGEN, U., STAUFFER, D. High-throughput nanoindentation for statistical and spatial property determination. JOM [online]. 2018, 70(4), p. 494-503. ISSN 1047-4838, eISSN 1543-1851. Available from: https://doi.org/10.1007/s11837-018-2752-0

[14] COOK, R. D. Detection of influential observations in linear regression. Technometrics [online]. 1977, 19(1), p. 15-18. ISSN 0040-1706, eISSN 1537-2723. Available from: https://doi.org/10.1080/00401706.1977.10489493 